\title{
Cultivar Resistance to Common Scab Disease of Potato Is Dependent on the Pathogen Species
}

\author{
Christopher R. Clarke, ${ }^{1, \dagger}$ Charles G. Kramer, ${ }^{1}$ Raghavendhar R. Kotha, ${ }^{2}$ \\ Leslie A. Wanner, ${ }^{1}$ Devanand L. Luthria, ${ }^{2}$ and Matthew Kramer ${ }^{3}$
}

\begin{abstract}
${ }^{1}$ Genetic Improvement for Fruits and Vegetables Laboratory, Beltsville Agricultural Research Center, U.S. Department of AgricultureAgricultural Research Service, Beltsville, MD 20705

${ }^{2}$ Food Composition and Methods Development Laboratory, Beltsville Human Nutrition Research Center, U.S. Department of AgricultureAgricultural Research Service, Beltsville, MD 20705

${ }^{3}$ Statistics Group, Northeast Area, U.S. Department of Agriculture-Agricultural Research Service, Beltsville, MD 20705

Accepted for publication 6 May 2019.
\end{abstract}

\begin{abstract}
Common scab of potato is a superficial tuber disease caused by Streptomyces species that produce the phytotoxin thaxtomin. Because common scab development is highly dependent on the effects of this single toxin, the current operating paradigm in common scab pathology is that a potato cultivar resistant to one strain of the common scab pathogen is resistant to all strains. However, cultivar resistance to common scab disease identified in one breeding program is often not durable when tested in other potato breeding programs across the United States. We infected 55 potato cultivar populations with three distinct species of the common scab pathogen

and identified cultivars that were resistant or susceptible to all three species and cultivars that had widely varying resistance dependent on the pathogen species. Overall lower virulence was associated with the strain that produces the least thaxtomin. This result showcases several cultivars of potato that are expected to be resistant to the majority of common scab populations but also highlights that many potato cultivars are resistant to only specific species of the pathogen. These results demonstrate that extension specialists and growers must consider their local population of the common scab pathogen when selecting which cultivars to plant for common scab resistance.
\end{abstract}

Common scab disease of potato is characterized by raised or pitted scabby lesions on tuber surfaces that reduce the marketability of tubers but not total yield (Braun et al. 2017a). The etiological agents of common scab are several soilborne species of Streptomyces. There are more than 800 named species of Streptomyces (bacterio.net 2019). Most Streptomyces species isolated from soil are harmless saprophytes. Several species are known to promote plant growth or are intensively studied because of their value as antibiotic-producing organisms (Chater 2016; Sousa and Olivares 2016). Only a few species of Streptomyces include major plant pathogens (Francis et al. 2010). Thus, one must assess subspecieslevel diversity to understand the ecological impact of local field population of Streptomyces species. The species known to cause common scab on potato in North America are S. stelliscabiei, S. scabiei, S. europaeiscabiei, Streptomyces sp. IdahoX, S. acidiscabiei, and S. turgidiscabiei (Braun et al. 2017a; Goyer and Beaulieu 1997; Wanner 2006, 2009; Zhou et al. 2017). In addition, S. ipomoea causes common scab of sweet potato (Clark and Matthews 1987) and $S$. reticuliscabiei causes the related but less severe netted scab disease (Bouchek-Mechiche et al. 2000). In North America, $S$. scabiei and S. europaeiscabiei are the species most commonly

†Corresponding author: C. R. Clarke; christopher.clarke@ars.usda.gov

Funding: This study was supported by U.S. Department of Agriculture-Agricultural Research Service Current Research Information System (CRIS) project number 8042-21000-283.

L. A. Wanner is deceased.

*The $\boldsymbol{e}$-Xtra logo stands for "electronic extra" and indicates that two supplementary figures and six supplementary tables are published online.

The author(s) declare no conflict of interest.

This article is in the public domain and not copyrightable. It may be freely reprinted with customary crediting of the source. The American Phytopathological Society, 2019. isolated from diseased tubers, followed by S. stelliscabiei and Streptomyces sp. IdahoX (Wanner 2009).

The one known commonality of all Streptomyces strains that cause common scab is that they produce the phytotoxin thaxtomin A (Kers et al. 2005; Loria et al. 2008). The thaxtomin A biosynthetic gene cluster is located on a mobile pathogenicity island (Bignell et al. 2010; Kers et al. 2005). Horizontal gene transfer of this pathogenicity island was potentially the driver for the emergence of several lineages of Streptomyces common scab pathogens (Bukhalid et al. 2002; Zhang et al. 2016). Conjugation of the thaxtomin biosynthetic cluster can convert nonpathogenic Streptomyces species into pathogens (Bukhalid and Loria 1997; Healy et al. 2000; Zhang et al. 2016). Deletion of genes in the thaxtomin biosynthetic cluster or associated regulatory elements from thaxtomin-producing Streptomyces pathogens eliminates pathogenicity (Joshi et al. 2007; Kers et al. 2004). The genes in the thaxtomin A biosynthetic cluster are used as a marker for pathogenicity in Streptomyces strains (Qu et al. 2008). Identifying potatoes resistant to the effects of thaxtomin is considered necessary for developing common scab-resistant cultivars. Indeed, resistance to thaxtomin has been used as a selective agent in somatic selection of scab-resistant plantlets (Wilson et al. 2009, 2010). It is also generally accepted that a potato cultivar resistant to one strain of common scabcausing Streptomyces is likely to be resistant to most other strains as well because all strains primarily rely on the same virulence factor.

Several potato cultivars are resistant to common scab (Braun et al. 2017a), and markers for common scab resistance were identified in a breeding population (Braun et al. 2017b). However, common scab resistance is lacking from many elite cultivars. Resistance to common scab is often screened during cultivar development in many of the potato breeding programs in the United States. However, clones that exhibit resistance to common scab in one program often are susceptible to the disease when they are released for testing by other breeding programs. This instability of resistance may be driven by environmental variables or differences in the pathogen populations. Here we test the hypothesis that defining a potato cultivar as resistant or susceptible to common scab is pathogen specific. 


\section{MATERIALS AND METHODS}

Potato cultivars/clones and Streptomyces pathogens used in this study. All potato cultivars tested in this study are listed in Table 1. The three species of common scab-causing Streptomyces tested in this study were Streptomyces sp. IdahoX strain ID01-12C, S. scabiei strain ME01-11h, and S. stelliscabiei strain NY02-1C or NY02-3A. These strains were originally isolated from common scab-infected tubers in Idaho, Maine, and New York, respectively (Wanner 2006, 2009).

TABLE 1. Potato cultivars and clones tested in this work

\begin{tabular}{|c|c|}
\hline Cultivar/clone ${ }^{\mathrm{a}}$ & Testing $^{\mathrm{b}}$ \\
\hline AF4013-3 & Year 2 only \\
\hline AF4157-6 & Year 2 only \\
\hline Alturas & Both years \\
\hline Atlantic & Both years \\
\hline B2727-2 & Year 2 only \\
\hline Bannock & Year 2 only \\
\hline Blazer & Both years \\
\hline BNC-182-5 & Year 2 only \\
\hline Burbank & Both years \\
\hline Burbank (ID) & $\begin{array}{l}\text { Both years; no data for } \\
\text { at least one pathogen }\end{array}$ \\
\hline Canela & Both years \\
\hline Chieftan & Year 2 only \\
\hline Chippewa & Year 2 only \\
\hline Classic & Year 2 only \\
\hline Dakota Pearl & Both years \\
\hline Dark Red Norland & Both years \\
\hline Green Mountain & Year 2 only \\
\hline Dakota Crisp & Year 2 only \\
\hline GoldRush & Both years \\
\hline Ivory Crisp & Year 2 only \\
\hline Katahdin & Year 2 only \\
\hline Kennebec & Year 2 only \\
\hline Megachip & Year 1 only \\
\hline Modoc & Year 2 only \\
\hline Norkotah & Year 2 only \\
\hline Norkotah-3 & Both years \\
\hline Norkotah-8 & Both years \\
\hline Norkotah-112 & Year 2 only \\
\hline Norkotah-278 & Year 2 only \\
\hline Norkotah-296 & Both years \\
\hline Norkotah (ID) & Year 1 only \\
\hline Norkotah (ND) & Year 1 only \\
\hline Norland & $\begin{array}{l}\text { Both years; no data for } \\
\text { at least one pathogen }\end{array}$ \\
\hline NY150 & Year 2 only \\
\hline NYE106-4 & Year 2 only \\
\hline Pike & Both years \\
\hline Premier & Both years \\
\hline Ranger & Both years \\
\hline Ranger Amisk & $\begin{array}{l}\text { Year } 2 \text { only; no data for } \\
\text { at least one pathogen }\end{array}$ \\
\hline Reba & Year 2 only \\
\hline Red LaSoda & Both years \\
\hline Red Maria & Year 2 only \\
\hline Rio Grande & Both years \\
\hline Shepody & Both years \\
\hline Silverton & Year 1 only \\
\hline Snowden & Both years \\
\hline Superior & Both years \\
\hline Superior (NY) & Year 2 only \\
\hline Umatilla & Year 2 only \\
\hline Western & Year 2 only \\
\hline Yukon Gem & Year 2 only \\
\hline Yukon Gold & $\begin{array}{l}\text { Year } 2 \text { only; no data for } \\
\text { at least one pathogen }\end{array}$ \\
\hline Yukon Gold (ID) & $\begin{array}{l}\text { Year } 1 \text { only; no data for } \\
\text { at least one pathogen }\end{array}$ \\
\hline Yukon Gold (ME) & Year 1 only \\
\hline Yukon Gold (WI) & $\begin{array}{l}\text { Year } 1 \text { only; no data for } \\
\text { at least one pathogen }\end{array}$ \\
\hline
\end{tabular}

\footnotetext{
a $\mathrm{ID}=$ Idaho, ND = North Dakota, NY = New York, ME = Maine, and WI = Wisconsin.

b Year $1=2012$, year $2=2013$.
}

Infection of potato with Streptomyces pathogens in greenhouse pot assays. Streptomyces inoculum was prepared by growing strains on standard yeast malt extract (YME; $4 \mathrm{~g}$ of yeast extract, $10 \mathrm{~g}$ of malt extract, and $4 \mathrm{~g}$ of dextrose per liter of $\mathrm{ddH}_{2} \mathrm{O}$ ) plates at $28^{\circ} \mathrm{C}$ for 14 days, suspending spores in sterile $\mathrm{H}_{2} \mathrm{O}$, and then using this spore suspension to inoculate $30 \mathrm{ml}$ of liquid YME. Spore suspensions in YME were then grown at $28^{\circ} \mathrm{C}$ with $190 \mathrm{rpm}$ shaking. After 3 days of incubation, bacterial cells were pelleted through centrifugation at $4,000 \mathrm{rpm}$ at $4^{\circ} \mathrm{C}$ for $15 \mathrm{~min}$, and cells were resuspended in sterile $\mathrm{H}_{2} \mathrm{O}$ to a final concentration of $0.15 \mathrm{~g} / \mathrm{ml}$. Two milliliters of this cell suspension was then inoculated into individual bags of approximately $45 \mathrm{~g}$ of vermiculite that had previously been autoclaved three times at 3-day intervals. The vermiculite bags were then incubated at $28^{\circ} \mathrm{C}$ for 14 days with kneading of the bags to mix the inoculum every 2 to 3 days. After 11 days, a small quantity of vermiculite from each bag was sampled, weighed, and vortexed in sterile $\mathrm{H}_{2} \mathrm{O}$ to release bacteria. A dilution series was plated onto YME plates and the number of CFU per gram of vermiculite was calculated 3 days later. All bags were then standardized to approximately $1 \times 10^{8} \mathrm{CFU} / \mathrm{g}$ vermiculite as the final inoculum.

Cold-stored tubers were rinsed with $\mathrm{H}_{2} \mathrm{O}$, dipped in $1.5 \%$ sodium hypochlorite for $2 \mathrm{~min}$, and then rinsed with $\mathrm{H}_{2} \mathrm{O}$ again. Tubers were then stored in the dark at room temperature for 3 to 6 days before planting. At planting, tubers were cut to include at least two sprouts on each seed piece. Pots were prepared by mixing 1:1 sand/potting mix (Sungrow professional growth mix; Sun Gro, Seba Beach, AB, Canada) with Streptomyces-containing vermiculite inoculum, added to an 8-inch pot, and then burying the seed pieces 1 to 2 inches under the soil line. Three replicate pots were included for each pathogen-cultivar combination in each year.

Scoring of severity of common scab disease and statistical analysis. Daughter tubers were collected and rinsed 14 weeks after planting. All tubers were defined as market grade or below market grade based on the type of lesion present on the tuber and the total coverage of the tuber in lesions using the criteria defined in Figure 1. Our data analyses were based on the proportion of below market grade tubers. To test for interactions and main
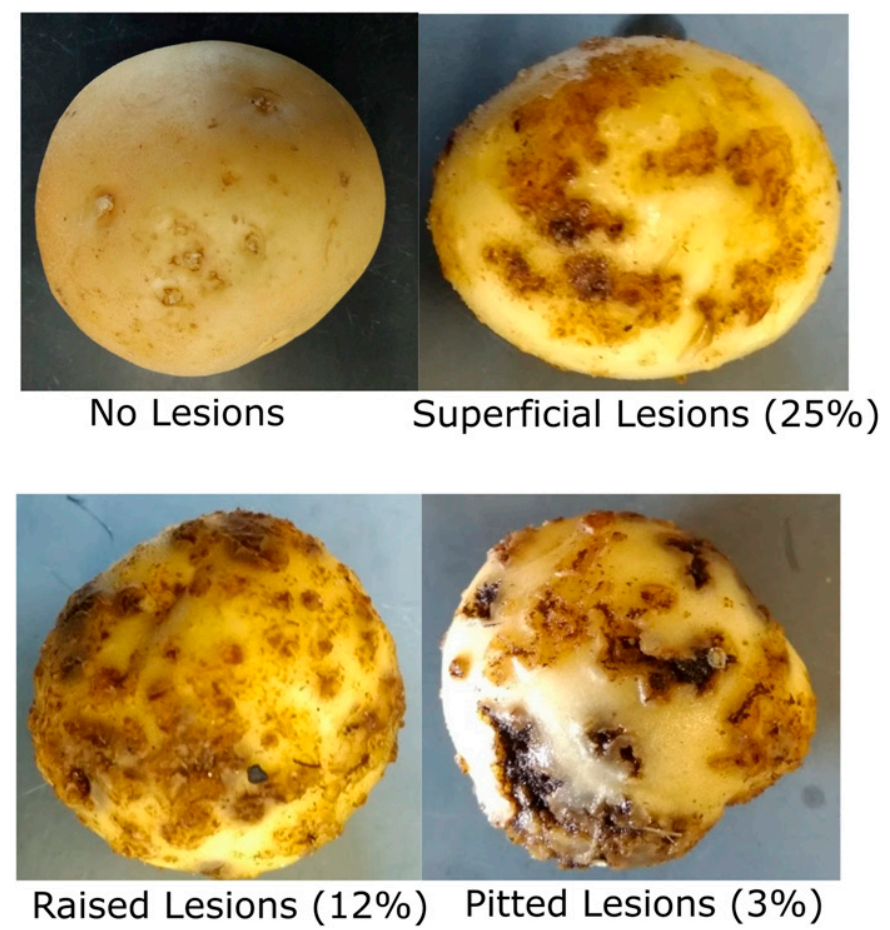

Fig. 1. Examples of common scab lesion types on Chippewa tubers. Percentages indicate the maximum percent surface coverage of each lesion to be considered "market grade" in the scab scoring system. 
effects, we used the subset of the data where cultivars and pathogen were present in both years. Individual plants (pots) were random effects and other effects (cultivar, pathogen, year) were fixed. We used the lmerTest package in R software (Kuznetsova et al. 2017; R Core Team 2018), where denominator degrees of freedom were estimated using the Satterthwaite approximation. For this analysis, the dependent variable was 0 or 1 (1 if the tuber was below market grade), analogous to a linear discriminant analysis with two categories. The usual logistic analysis was not possible because many combinations of factors had all bad or all good tubers. A variance decomposition using the same data and model, but with all terms treated as random effects, was also conducted. Other descriptive statistics were conducted with the full data set or other subsets, as described below.

The data and R script were uploaded to the Ag Data Commons (https://data.nal.usda.gov/dataset/data-cultivar-resistance-commonscab-disease-potato-dependent-pathogen-species).

Extraction of thaxtomin-containing cell-free extracts from Streptomyces strains grown in liquid culture. Streptomyces strains were grown in oat bran broth (OBB) (Babcock et al. 1993), which induces production of thaxtomin (Beauséjour et al. 1999), for 7 days. Cell cultures were centrifuged for $20 \mathrm{~min}$ at $3,300 \times g$ at $4^{\circ} \mathrm{C}$, stored at $4^{\circ} \mathrm{C}$ overnight, and then centrifuged again for $20 \mathrm{~min}$ at $3,300 \times g$ at $4^{\circ} \mathrm{C}$. To make the cell-free extracts, the supernatants were collected and filtered through a $0.2-\mu \mathrm{M}$ Whatman PES filter.

Thaxtomin was further purified from the cell-free extracts following the procedure of Johnson et al. (2007) with slight modifications. Briefly, C18 columns (Thermo Fisher Scientific, Waltham, MA) were conditioned by flowing $3 \mathrm{ml}$ of $100 \%$ methanol through the column, followed by $3 \mathrm{ml}$ of $\mathrm{ddH}_{2} \mathrm{O}$, and then $3 \mathrm{ml}$ of $25 \%$ methanol. Twelve milliliters of the cell-free culture extract was applied to the column. Thaxtomin was then eluted using $100 \%$ methanol. The first $290 \mu \mathrm{l}$ of the eluate (clear) was discarded and the following $240 \mu \mathrm{l}$ of the eluate (dark yellow) was retained for downstream analysis.

Quantification of thaxtomin by high-performance liquid chromatography. An Agilent 1100 high-performance liquid chromatography (HPLC) system coupled with Agilent LC/MSD SL (Agilent Technologies, Santa Clara, CA) was used to quantify thaxtomin concentrations. Stock solution of thaxtomin was diluted in methanol to yield final concentrations for calibration standards $(1,2,5,10,25,50$, and $100 \mu \mathrm{M})$. Intrarun quality control (QC) samples were freshly prepared at 1, 5, and $25 \mu \mathrm{M}$. A UV detector $(380 \mathrm{~nm})$ was used for the quantification of thaxtomin and mass spectrometry (MS) was used for the mass $(\mathrm{m} / \mathrm{z}$ ) confirmation. Cell-free extract samples were analyzed without diluting and the purified thaxtomin samples were diluted 20 times with methanol prior to analysis. The separation of thaxtomin was carried

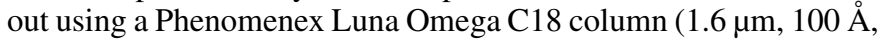

$150 \times 2.1 \mathrm{~mm}$ ) equipped with a Phenomenex guard column. The column was maintained at $50^{\circ} \mathrm{C}$ and the flow rate for the separation was $0.4 \mathrm{ml} / \mathrm{min}$. Water (solvent A) and acetonitrile (solvent B) were used as mobile phases. The sample injection volume was $10 \mu \mathrm{l}$. Total chromatography runtime was $10 \mathrm{~min}$. The solvent gradient was as follows: 0 to $6 \mathrm{~min}, 10$ to $70 \%$ solvent B; 6 to $6.2 \mathrm{~min}, 70$ to $95 \%$ solvent $\mathrm{B} ; 6.2$ to $7.8 \mathrm{~min}, 95 \%$ solvent $\mathrm{B} ; 7.8$ to $8.0 \mathrm{~min}, 95$ to $10 \%$ solvent B; and 8.0 to $10.0 \mathrm{~min}, 10 \%$ solvent B. Mass spectra were obtained using electrospray ionization in positive mode within a mass range of 100 to $500 \mathrm{~m} / \mathrm{z}$. MS conditions were as follows: needle voltage, $3,000 \mathrm{~V}$; capillary voltage, $70 \mathrm{~V}$; probe temperature, $300^{\circ} \mathrm{C}$; and nitrogen (drying gas) pressure, 80 psi. A typical chromatogram of thaxtomin standard and sample is shown in Supplementary Figure S1. Data acquisition and analysis was performed using Chromeleon software 7.2 (Thermo Fisher Scientific, Waltham, MA).

The developed method was validated for linearity range, accuracy, precision, limit of detection (LOD), and limit of quantification (LOQ) for thaxtomin as per International Council for Harmonisation of Technical Requirements for Pharmaceuticals for Human Use (2005) guidelines. The calibration curve was plotted using log (concentration) versus $\log$ (thaxtomin area) for seven different concentrations. Precision (percent relative standard deviation) was equal to (standard deviation $/$ mean $) \times 100$. Accuracy was measured as a percentage of the obtained value divided by the intended value. The analytical data for the thaxtomin quantification is presented in Supplementary Table S1. Thaxtomin showed good linearity $(y=1.0374 x-4.3493$, $r^{2}=0.9998$ ) for the linearity range of 1 to $100 \mu \mathrm{M}$. QC samples (low, medium, and high) were used to determine precision (\%RSD) and accuracy. Precision and accuracy data for all QC samples were determined to be within an acceptable range $(<15 \%)$. LOD and LOQ for the current method were 0.12 and $0.37 \mu \mathrm{M}$, respectively. LOD and LOQ were calculated for six replicates of a single standard as 3.3/10 times the standard deviation for a single standard divided by the slope of the calibration curve (International Council for Harmonisation of Technical Requirements for Pharmaceuticals for Human Use 2005; Lindqvist et al. 2018).

Quantitative reverse transcription PCR. Streptomyces strains were grown in thaxtomin-inducing OBB or nonthaxtomininducing YME for 2 days. Cells were harvested by centrifugation and RNA was extracted using a Qiagen RNeasy kit (Qiagen, Hilden, Germany). cDNA was synthesized using a Bio-Rad iScript cDNA synthesis kit (Bio-Rad, Hercules, CA). Quantitative reverse transcription PCR was performed using Bio-Rad iTaq Universal SYBR Green mix with the $t x t A B$ primers described in $\mathrm{Qu}$ et al. (2008) and reference genes $s c a b \_53121$ and $s c a b \_36331$ described in Li et al. (2015) on a Bio-Rad CFX connect thermocycler using an annealing temperature of $60^{\circ} \mathrm{C}$. Specificity of primer annealing was confirmed by melt curve and gel analysis. One potential reference gene, scab_74581 (Li et al. 2015), was removed from the analysis

TABLE 2. Analysis of variance of a mixed linear model

\begin{tabular}{|c|c|c|c|c|c|c|}
\hline \multirow[b]{2}{*}{ Effect } & \multirow[b]{2}{*}{ Sum of squares } & \multicolumn{2}{|c|}{ Degrees of freedom } & \multirow[b]{2}{*}{$F$ value } & \multirow[b]{2}{*}{$P$ value } & \multirow[b]{2}{*}{ Total variation $(\%)$} \\
\hline & & Numerator & Denominator $^{\mathrm{a}}$ & & & \\
\hline \multicolumn{7}{|l|}{ Fixed } \\
\hline Cultivar & 11.7 & 19 & 148.9 & 4.4 & $<0.0001$ & 9.51 \\
\hline Pathogen & 10.7 & 1 & 161.7 & 75.4 & $<0.0001$ & 23.22 \\
\hline Year & 0.3 & 1 & 163.4 & 1.8 & 0.1833 & 0.00 \\
\hline Cultivar $\times$ pathogen & 5.6 & 19 & 146.2 & 2.1 & 0.0078 & 7.42 \\
\hline Cultivar $\times$ year & 2.0 & 19 & 143.6 & 0.7 & 0.7642 & 0.00 \\
\hline Pathogen $\times$ year & 0.4 & 1 & 148.7 & 3.1 & 0.0789 & 1.08 \\
\hline \multicolumn{7}{|l|}{ Random } \\
\hline Plant (pot) & & & & & & 9.89 \\
\hline Discreteness error & & & & & & 32.66 \\
\hline Residual (tuber) & & & & & & 16.22 \\
\hline
\end{tabular}

a Satterthwaite approximation for degrees of freedom. 
based on the presence of multiple amplicons. Relative $t x t A B$ expression was calculated for each biological group across all technical replicates using Bio-Rad CFX Maestro software. $t x t A B$ expression data required transformation prior to analysis because standard deviations (calculated from technical replicates) were clearly a function of the mean. A rank-inverse normal transformation
(Cai et al. 2016) was used, because this transformation both removes the dependence of standard deviations on their means and allows for testing in a parametric framework because the transformed data will satisfy normality assumptions. Analysis was conducted using analysis of variance (ANOVA) (base R) followed by tests of linear contrasts of interest (using the emmeans $\mathrm{R}$ package). No $P$ value

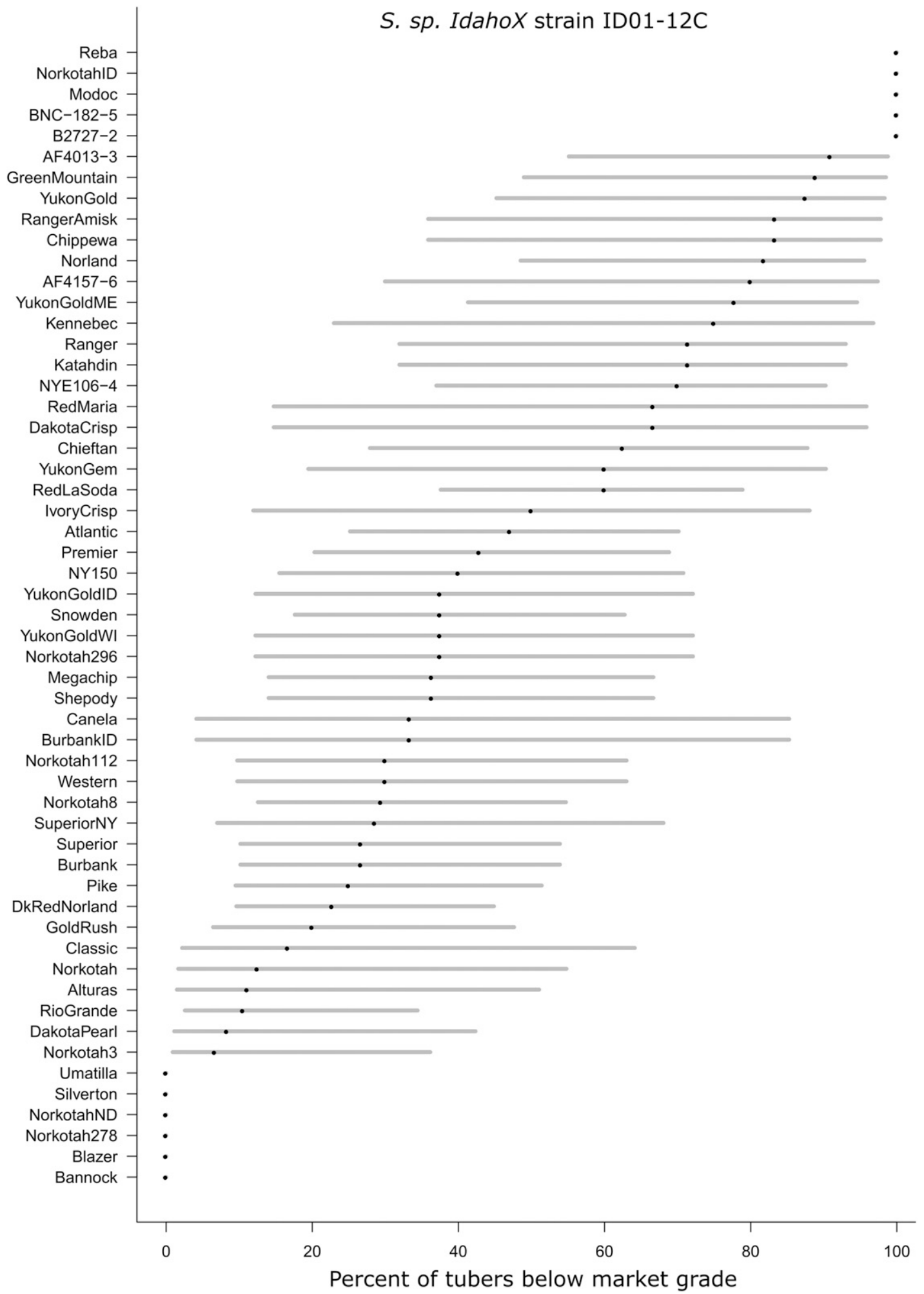

Fig. 2. Susceptibility of potato cultivars to strain Streptomyces sp. IdahoX strain ID01-12C. Black points represent the mean estimate of the percentage of tubers that were classified as below market grade for each cultivar after infection of Streptomyces sp. IdahoX strain ID01-12C. Shaded gray bars represent the 95\% confidence interval. For cultivars with no indicated $95 \%$ confidence, all tubers were ranked as either market grade or below market grade uniformly, so the variance was zero (no confidence interval possible). 
adjustments were necessary because these were one degree of freedom a priori linear contrasts.

Phytotoxicity of thaxtomin-containing cell-free extracts from Streptomyces liquid culture. Arabidopsis seeds were sterilized by soaking for $30 \mathrm{~s}$ in $1.5 \%$ sodium hypochlorite and for $30 \mathrm{~s}$ in $70 \%$ ethanol and then rinsed three times with $\mathrm{ddH}_{2} \mathrm{O}$. Seeds were stratified for 2 to 4 days in $\mathrm{ddH}_{2} \mathrm{O}$ at $4{ }^{\circ} \mathrm{C}$ and then planted in $0.8 \%$ agar nutrient medium plates (Lejay et al. 1999) spiked with pooled thaxtomin from liquid cultures of each of the indicated Streptomyces strains. Plates were sealed with micropore surgical tape (3M, Maplewood, $\mathrm{MN}$ ) and stored in a dark box at $22^{\circ} \mathrm{C}$. The hypocotyl length of each etiolated seedling was measured 7 days after planting.

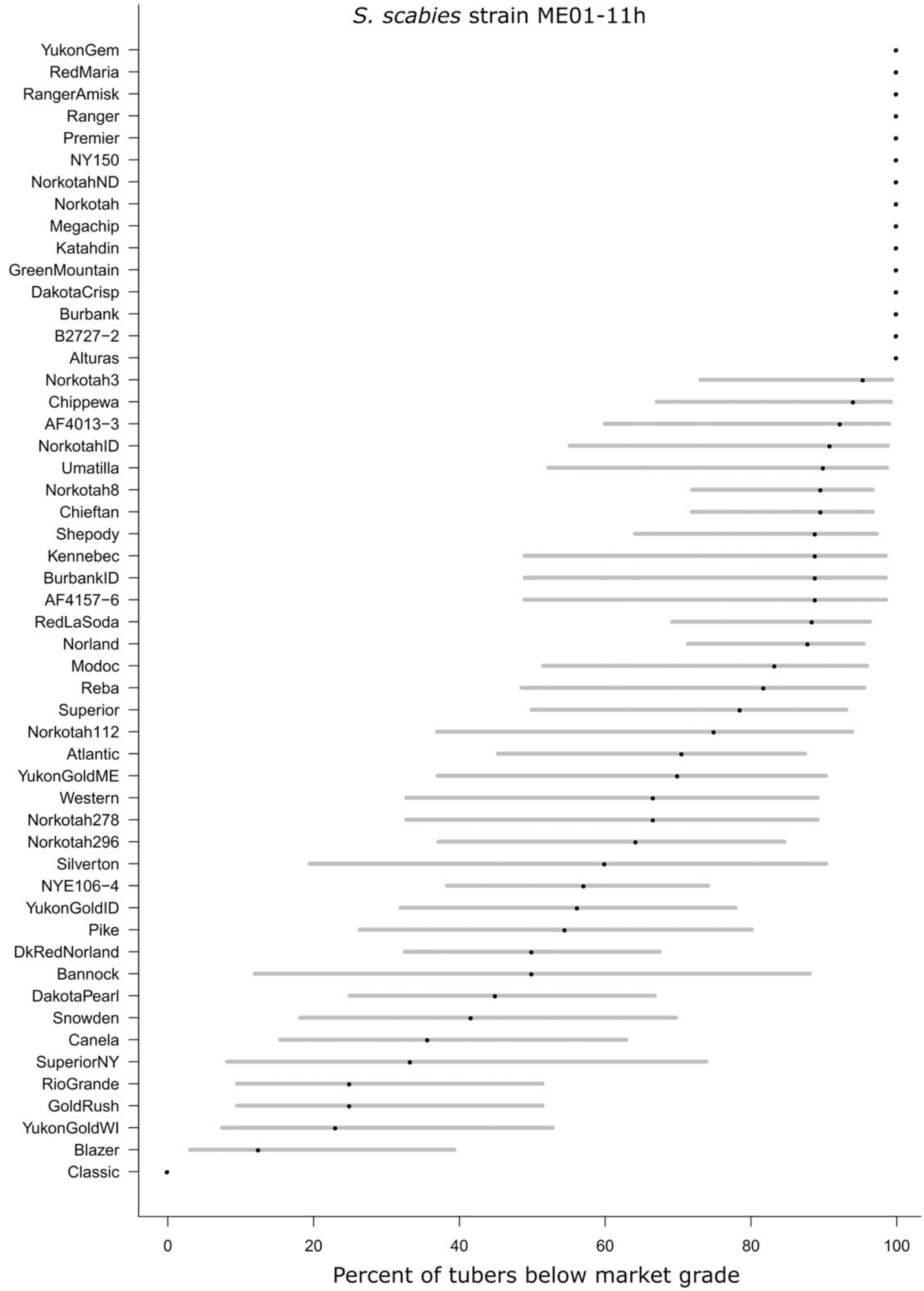

Fig. 3. Susceptibility of potato cultivars to Streptomyces scabiei strain ME01-11h. Black points represent the mean estimate of the percentage of tubers that were classified as below market grade for each cultivar after infection of S. scabiei strain ME01-11h. Shaded gray bars represent the 95\% confidence interval. For cultivars with no indicated 95\% confidence, all tubers were ranked as either market grade or below market grade uniformly, so the variance was zero (no confidence interval possible). 


\section{RESULTS}

The susceptibility of 55 potato cultivar populations to three species of Streptomyces that cause common scab. Thirty-eight distinct potato cultivars were individually challenged with three different species of Streptomyces that cause common scab: Streptomyces sp. IdahoX strain ID01-12C, S. scabiei strain ME01-11h, and S. stelliscabiei strain NY02-1C or NY02-3A. An additional two cultivars were challenged with Streptomyces sp. IdahoX strain ID01-12C and S. scabiei strain ME01-11h only. Four cultivars (Yukon Gold, Russet Norkotah, Superior, and Russet Burbank) were tested with tubers sourced from different geographic

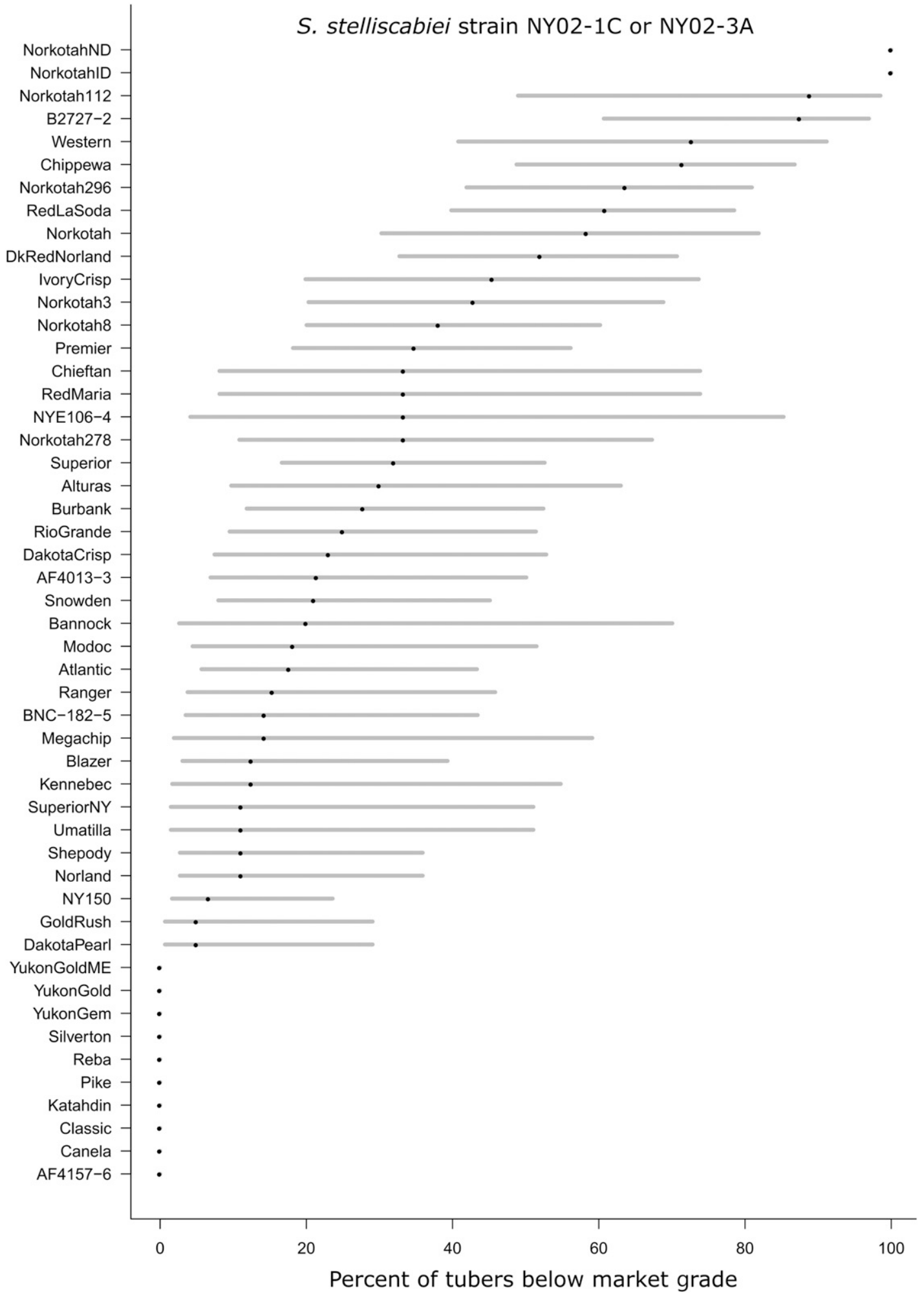

Fig. 4. Susceptibility of potato cultivars to Streptomyces stelliscabiei strain NY02-1C and NY02-3A. Black points represent the mean estimate of the percentage of tubers that were classified as below market grade for each cultivar after infection of S. stelliscabiei strain NY02-1C (year 1) or NY02-3A (year 2). Shaded gray bars represent the 95\% confidence interval. For cultivars with no indicated 95\% confidence, all tubers were ranked as either market grade or below market grade uniformly, so the variance was zero (no confidence interval possible). 
locations, for a total of 55 cultivar populations being tested (Table 1). All individual tuber disease ratings for each pathogencultivar combination are available in Supplementary Table S2. Each tuber was graded as "market grade" or "below market grade" (Fig. 1). A subset of the data, 20 of the cultivars and the two pathogen strains present in both years, was used to test main effects and interactions. As shown in Table 2, the cultivar, the pathogen, and the cultivar-pathogen interaction were significant predictors of whether a tuber was graded as market grade or below market grade. Neither the year, year-pathogen, nor year-cultivar interactions were significant. Therefore, data from both years were combined for downstream analyses. The linear model error term was partitioned into that part attributable to pot-to-pot variation and that part attributable to the discrete nature of the dependent variable. That is, had the dependent variable been continuous, with values between zero and one, the variance would be about two-thirds less. Approximately $16 \%$ of the variance can be attributed to individual

TABLE 3. Ordered ranking of variance of the proportion of tubers below market grade for each tested pathogen across all cultivars

\begin{tabular}{llcc}
\hline Pathogen & Variance & Mean & Cultivars tested $(n)$ \\
\hline NY02-3A & 0.06286926 & 0.2584536 & 45 \\
ME01-11h & 0.0744966 & 0.7500298 & 52 \\
ID01-12c & 0.10202061 & 0.4638925 & 55 \\
NY02-1C & 0.11650864 & 0.3458311 & 25 \\
\hline
\end{tabular}

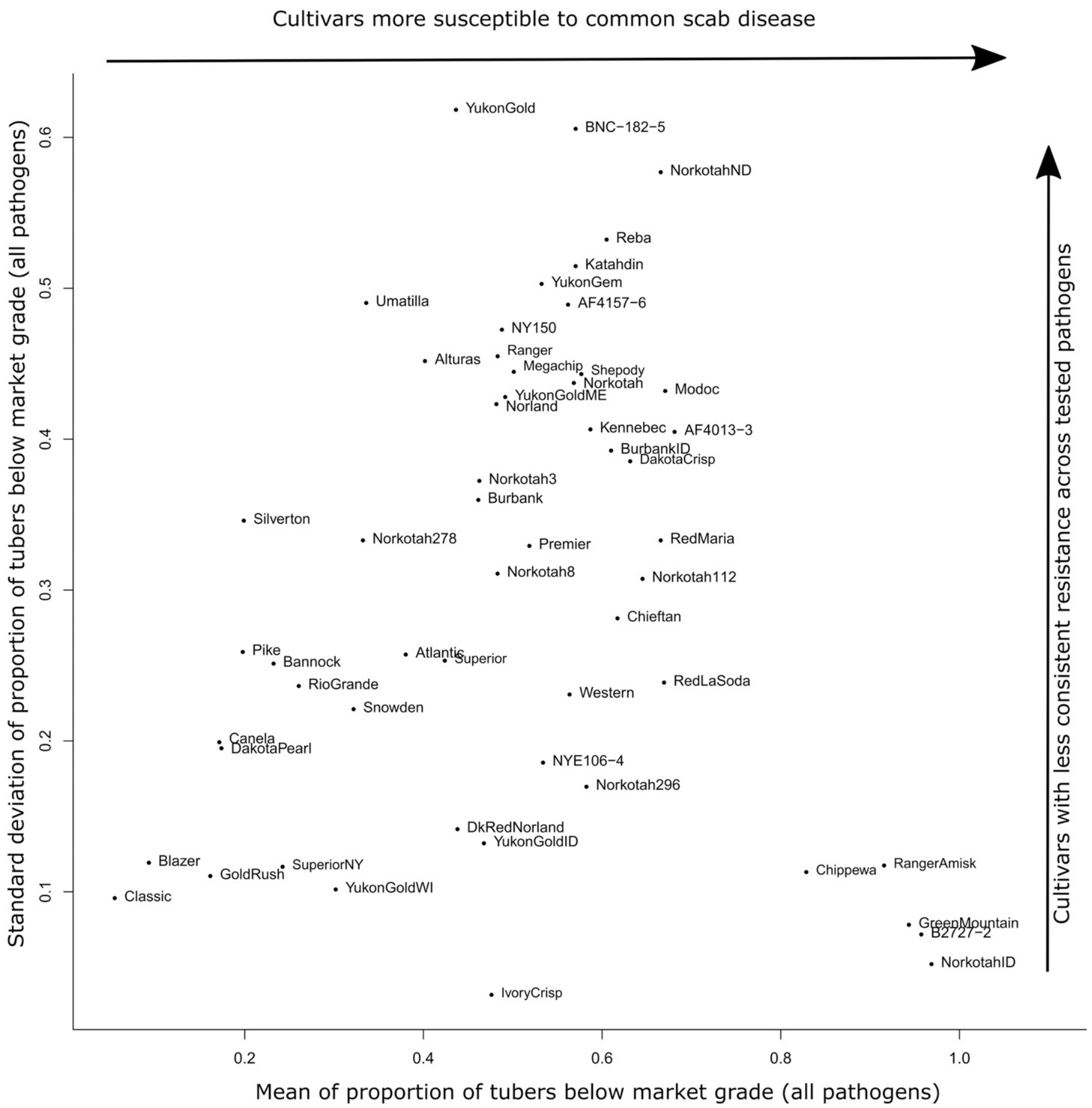

Fig. 5. Relationship of mean severity and consistency (standard deviation) of common scab disease caused by the three tested pathogen species for each potato cultivar. Each cultivar is plotted by the mean and standard deviation estimates of the percentage of tubers that are below market grade across all tested pathogens. 
pots (Table 2, last column), representing tuber-to-tuber variability within a plant (Table 2).

For each pathogen, the response of the tested cultivars ranged from fully resistant (defined as all tubers being market grade) to fully susceptible (defined as all tubers being below market grade) with numerous intermediate phenotypes (Figs. 2, 3, and 4; the error bars represent $95 \%$ confidence intervals on the proportions, calculated on the logit scale and back-transformed to the original scale). S. scabiei strain ME01-11h was the most aggressive pathogen (Fig. 3) and S. stelliscabiei strains NY02-1C and NY02$3 \mathrm{~A}$ were the least aggressive (Fig. 4) for the majority of cultivars. For most cultivars, resistance or susceptibility to one pathogenic species was a good predictor of resistance or susceptibility to the other pathogens. However, there are several notable exceptions. The cultivars Yukon Gold, Reba, NY150 (now Upstate Abundance), and Katahdin were resistant to the S. stelliscabiei strains but highly susceptible to Streptomyces sp. IdahoX strain ID01-12C and S. scabiei strain ME01-11h. This is in line with the general trend of $S$. stelliscabiei being the least aggressive pathogen. In contrast, the $S$. stelliscabiei strains were highly virulent on most of the tested clones of the Norkotah cultivar, whereas Norkotah was, in general, resistant to Streptomyces sp. IdahoX strain ID01-12C.

Resistance to common scab is pathogen specific for several potato cultivars. To better understand the extent to which common scab resistance is pathogen specific, we plotted the mean against the standard deviation estimates of the percentage of tubers that were below market grade for all 55 cultivar populations across all tested pathogens (Fig. 5). Cultivars with low standard deviation across all of the pathogens can more consistently be defined as susceptible or resistant to common scab. Cultivars with notable discrepancies in predicted susceptibility to different pathogen species (discussed above) and a high variance estimate, such as Yukon Gold, Reba, and NY150 (Fig. 5; Supplementary Table S3), are hypothesized to have pathogen-specific resistance or susceptibility determinants. Although all four tested pathogens had similar variances across all tested potato cultivars (Table 3), a
A

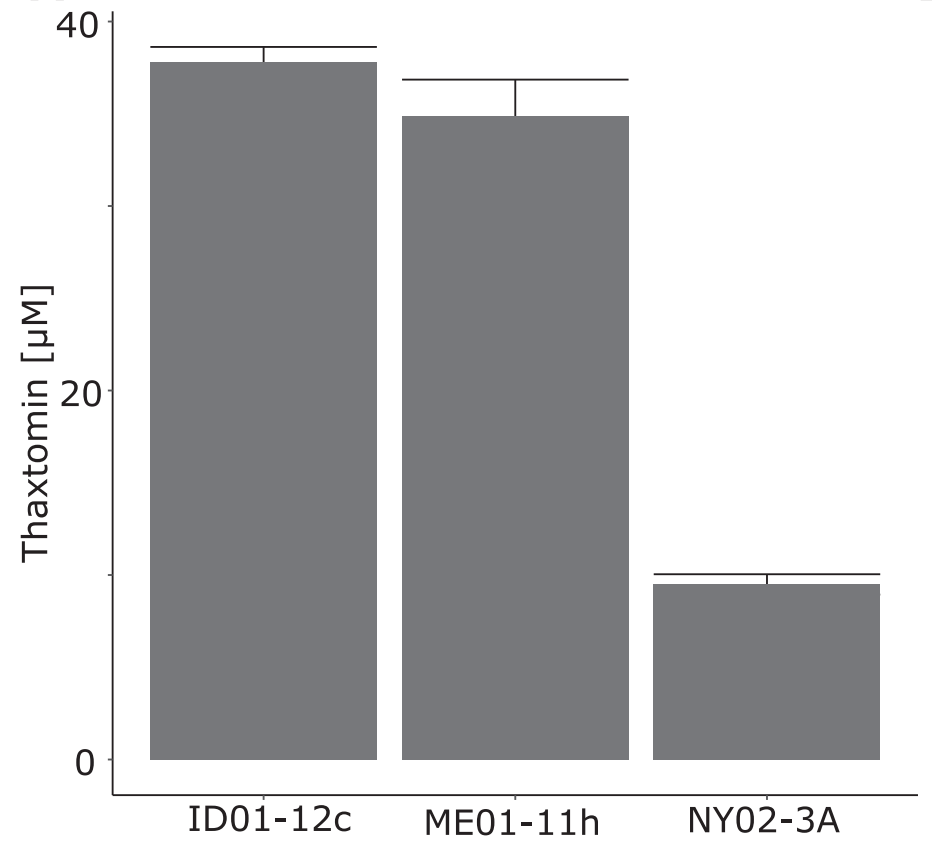

B

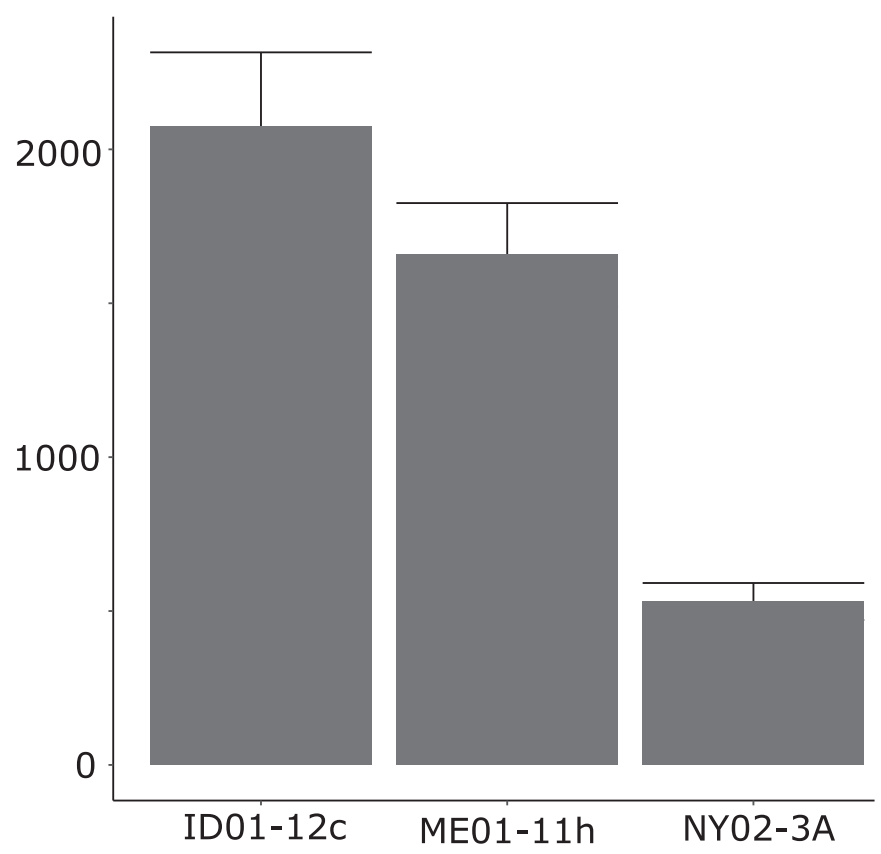

C

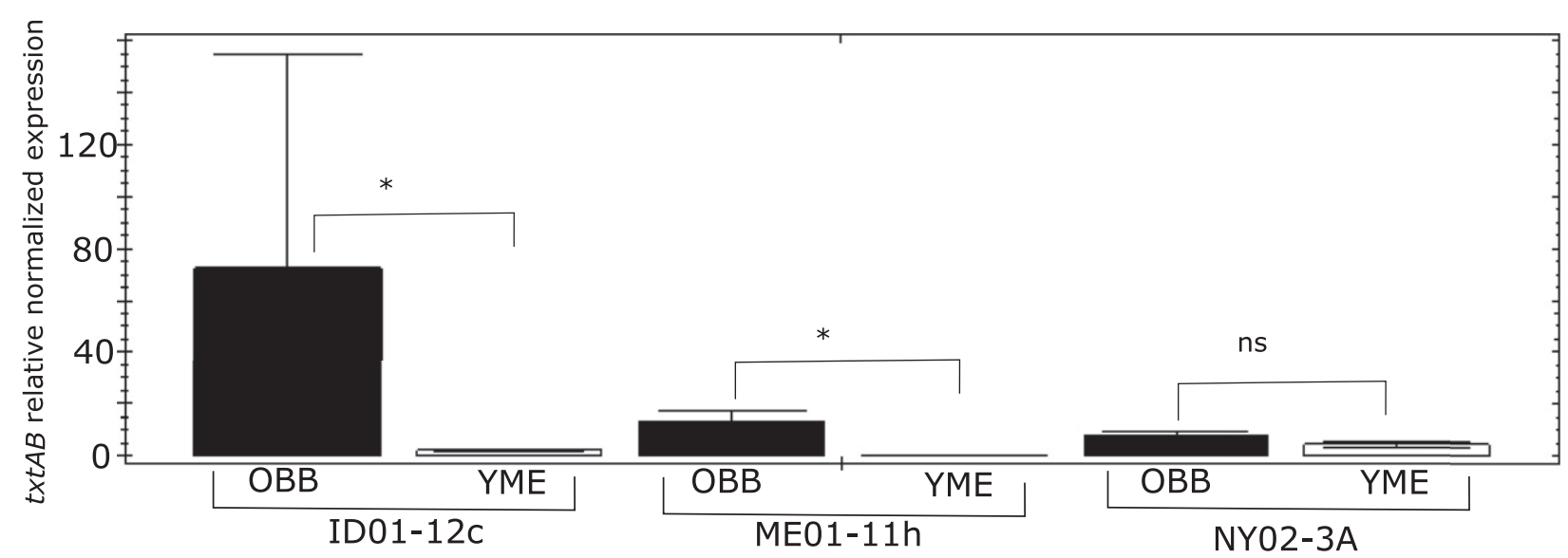

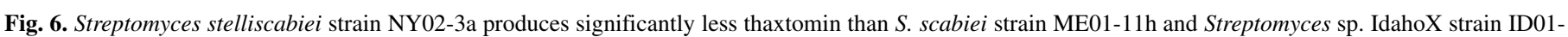

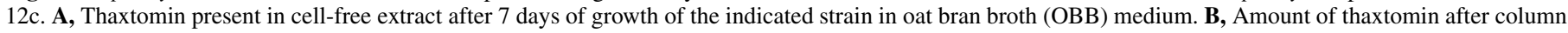

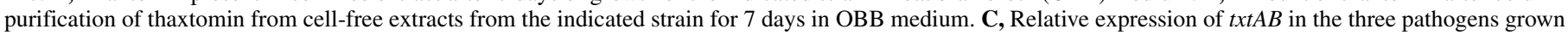

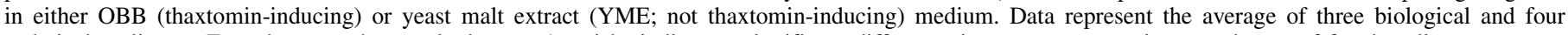

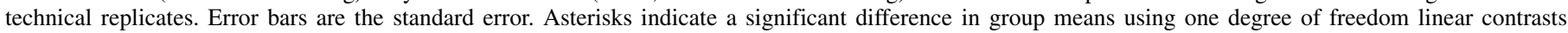

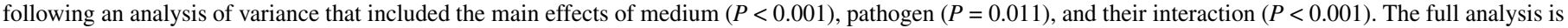
shown in Supplementary Table S6. $t x t A B$ gene expression was normalized to two reference genes (see the Materials and Methods). ns = not significant. 
sample of four was not sufficient for understanding the true diversity of virulence across pathogen populations.

Local source of potato tubers does not significantly affect susceptibility to common scab pathogens. For the cultivars Russet Norkotah, Russet Burbank, Yukon Gold, and Superior, we tested multiple sources of tubers in parallel to determine whether different sources of the tubers affect susceptibility to common scab. In general, cultivars displayed similar mean susceptibility/resistance to common
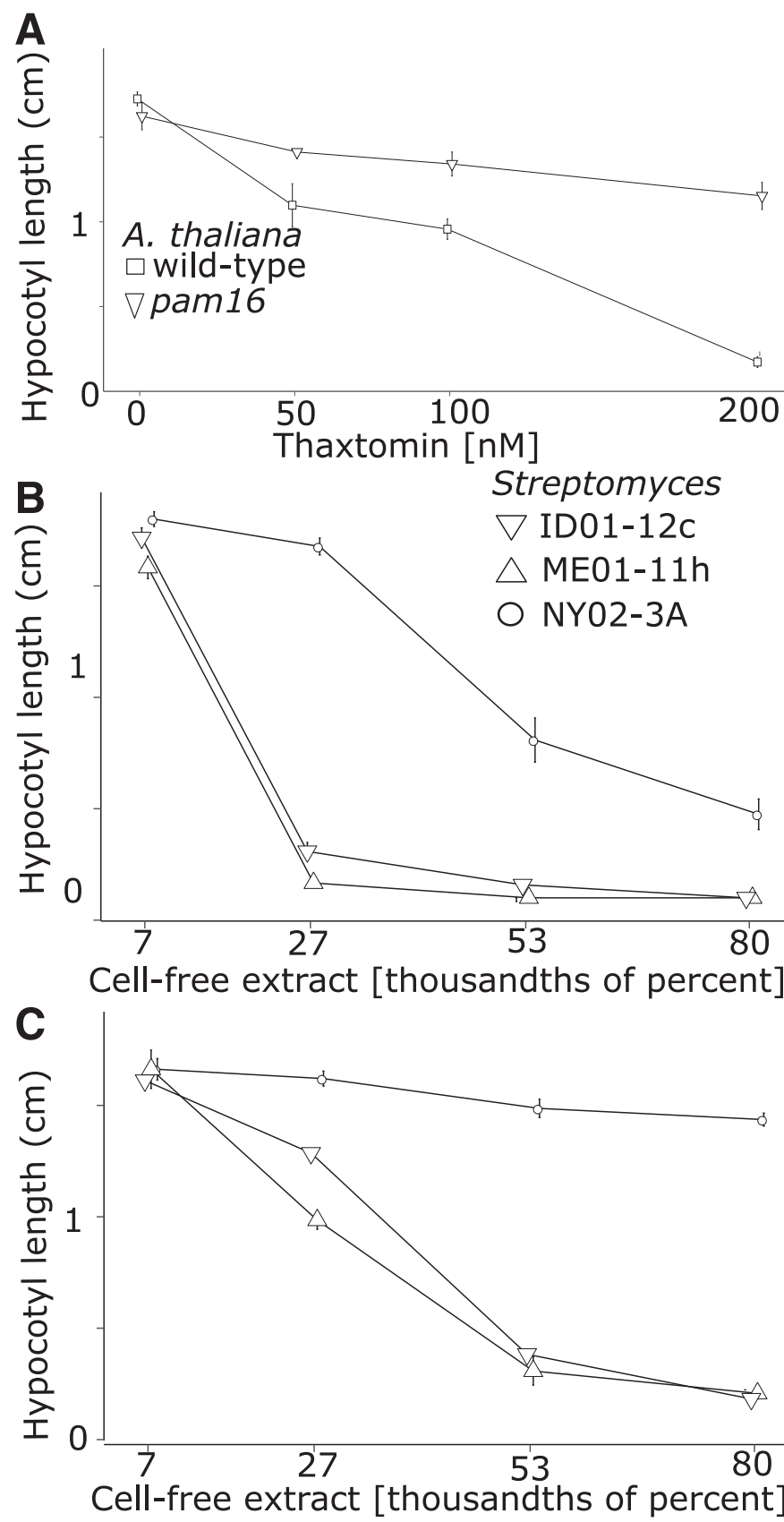

Fig. 7. Cell-free extracts from Streptomyces scabiei strain ME01-11h and Streptomyces sp. IdahoX strain ID01-12c inhibit plant growth more than cellfree extracts from S. stelliscabiei strain NY02-3a. A, Growth of wild-type Col0 or pam16 etiolated seedlings in plant growth medium spiked with thaxtomin. pam16 plants are less sensitive to thaxtomin-induced stunting. The 0-nM thaxtomin plates contained equivalent methanol to the 100-nM thaxtomin plates. Growth of B, wild-type or $\mathbf{C}$, pam16 mutant Arabidopsis in plant growth medium plates spiked with the indicated amounts of cell-free extracts from each of the three Streptomyces pathogenic strains. $n=4$ plants. Error bars represent the standard error. Essentially identical results were obtained in two independent experiments. Cell extracts for B and $\mathrm{C}$ were collected from four independent liquid cultures of each strain through centrifugation and $0.22-\mu \mathrm{M}$ filtration and then pooled together for each independent experiment. scab regardless of their source but had different standard deviation estimates (Fig. 5). The small number of replicates (three to six from most cultivar-pathogen combinations) was sufficient to estimate the mean of disease susceptibility but was not sufficient to estimate the variance, as good variance estimates typically require sample sizes of 20 or more. Therefore, the estimates of means are much better than the estimates of standard deviations.

The one notable exception of different populations of a cultivar having similar mean estimates was Russet Norkotah. Most Russet Norkotah clones exhibited similar disease ratings across the three pathogens (seven of the tested clones had mean disease scores between 33 and $66 \%$ of tubers below market grade). Yet Norkotah (ID), which was sourced from Idaho, had a mean disease score rating of $97 \%$ of tubers below market grade. This outlier was driven by susceptibility to Streptomyces sp. IdahoX strain ID01-12C, which exhibited low virulence on most Russet Norkotah clones but was highly virulent on the Norkotah (ID) tubers. We also found that Yukon Gold (ID) and Yukon Gold (WI) had much lower variances (but similar means) than the other tested Yukon Gold clones. However, this result is likely attributable to these clones not being challenged with the less virulent $S$. stelliscabiei strains.

S. stelliscabiei strain NY02-3A produces less thaxtomin than Streptomyces sp. IdahoX strain ID01-12c and S. scabiei strain ME01-11h. To estimate thaxtomin production by each of the three Streptomyces pathogens, we grew the strains in OBB medium, which stimulates the production of thaxtomin (Beauséjour et al. 1999), and then employed HPLC to quantify the amount of thaxtomin in both the "raw" cell-free extracts and from further purified thaxtomin. S. stelliscabiei strain NY02-03A produced significantly less thaxtomin than either $S$. scabiei strain ME01-11h or Streptomyces sp. IdahoX strain ID01-12c (Fig. 6A and B). Thaxtomin A is the only form of thaxtomin detected in any of the samples (Supplementary Fig. S2). The small peak following the main thaxtomin peak in some of the samples was confirmed by MS analysis to have the molecular weight of thaxtomin $\mathrm{A}(\mathrm{m} / \mathrm{z}, 439[\mathrm{M}+\mathrm{H}])$ and may be a thaxtomin A orthoisomer (Hiltunen et al. 2006).

In addition, we evaluated the expression of the core thaxtomin biosynthetic genes $t x t A B$ (Healy et al. 2000) of $S$. scabiei strain ME01-11h, Streptomyces sp. IdahoX strain ID01-12c, and S. stelliscabiei strain NY02-03A in thaxtomin-inducing OBB medium compared with nonthaxtomin-inducing YME medium. Because of the disparate variances of the $t x t A B$ expression data, we performed a rank-inverse normal transformation of the data (Cai et al. 2016; Supplementary Table S4). ANOVA of the transformed data confirmed that the pathogen $(P=0.011)$, the medium $(P<$ $0.001)$, and the pathogen-medium interaction $(P<0.001)$ all significantly affected $t x t A B$ expression (Supplementary Table S5). Interestingly, OBB medium induced $t x t A B$ expression for $S$. scabiei strain ME01-11h and Streptomyces sp. IdahoX strain ID01-12c but not S. stelliscabiei strain NY02-03A, suggesting that thaxtomin production is regulated differentially in this strain compared with other known Streptomyces pathogens (Fig. 6C).

To further test the phytotoxicity of the cell-free extracts produced by each of the three pathogenic Streptomyces strains, we measured the extent of plant stunting caused by cell-free extracts from each of the three pathogenic Streptomyces strains. Arabidopsis plants grown in the presence of thaxtomin in etiolating conditions were severely stunted (Fig. 7A) (Scheible et al. 2003). Arabidopsis plants defective in the putative mitochondrial inner membrane chaperone protein pam16 (Huang et al. 2013) (previously known as muse5 and txtrl) were significantly less sensitive to thaxtomin (Fig. 7A) (Scheible et al. 2003). Cell-free extracts from S. stelliscabiei strain NY02-3a inhibited plant growth substantially less than cell-free extracts from Streptomyces sp. IdahoX strain ID01-12c or S. scabiei strain ME01-11h (Fig. 7B). Stunting of plant growth occurred only at substantially higher concentrations of cell-free extracts for pam16 Arabidopsis plants (Fig. 7C). Therefore, we conclude that the observed stunting is primarily attributable to thaxtomin. 


\section{DISCUSSION}

This work demonstrates that a potato cultivar resistant to one species of the common scab pathogen may not be resistant to all other common scab pathogens. We observed marked differences in the general aggressiveness of three tested pathogenic species (Figs. 2,3 , and 4). Given the differing but well-estimated means and small variance estimates among the pathogens (Table 3), we can describe S. scabiei strain ME01-11h as the most aggressive tested pathogen. The variance estimates for the pathogens are more accurate than these estimates for the cultivars given the large number of cultivars tested on each pathogen. A larger sample of pathogens should be investigated in future work to better determine the extent to which the pathogen population is critical for defining a potato cultivar as susceptible or resistant to common scab.

This work suggests that higher thaxtomin production is associated with higher virulence for Streptomyces strains that cause common scab. We demonstrate that the lower virulence of $S$. stelliscabiei strain NY02-3a on several of the cultivars is associated with the lower amount of thaxtomin produced by this strain (Fig. 6B) and the lower extent of phytotoxic effects of cell-free extracts from this strain (Fig. 7). In addition, $t x t A B$ expression is not upregulated in S. stelliscabiei strain NY02-3A when grown in OBB medium unlike for the other tested pathogens (Fig. 6C). We do not know whether the S. stelliscabiei species in general produces less thaxtomin than S. scabiei or if this finding is specific to the tested strains.

For the cultivars that were more susceptible to $S$. stelliscabiei than one of the other tested pathogens, virulence determinants other than thaxtomin or pathogen-specific resistance elicitors must be driving pathogen-dependent variability in cultivar common scab resistance. In addition, the amount of thaxtomin produced by each pathogenic strain may vary in a cultivar-dependent manner. Cellobiose and suberin are the only known major inducers of thaxtomin production (Lerat et al. 2009), but perhaps other inducers exist, or different strains have differential capability for accessing or releasing cellobiose or suberin from roots and tubers.

Given the limited nature of this data set, these results should not be used to make decisions about which clones to plant for scab resistance. However, the results indicate the likely magnitude of future trials required for making informed recommendations on common scab resistance. Genotypes that exhibit a high degree of disease resistance and low variance across the pathogens (e.g., Blazer) will require fewer confirmatory disease resistance trials than genotypes that exhibit intermediate resistance and more variance across the pathogens (e.g., Yukon Gold; Fig. 5). In general, potato cultivar resistance/susceptibility in these assays matches most previously available field data for common scab resistance (Haynes et al. 2010).

In addition, the binary scoring system (market grade or below market grade; Fig. 1), while having high real-world relevance, is the noisiest possible scoring system, making the $95 \%$ confidence intervals for the estimates of disease severity (Figs. 2, 3, and 4) large for any cultivar-pathogen combination and not estimable for combinations where all tubers were above or below market grade. Nevertheless, we were able to definitively demonstrate that the pathogen species matters for defining a potato cultivar as resistant or susceptible to common scab disease (Table 2). Therefore, one must consider the local population of pathogenic Streptomyces strains when deciding which cultivars to plant on the basis of common scab resistance.

\section{ACKNOWLEDGMENTS}

We thank Kathleen Haynes (U.S. Department of Agriculture Agricultural Research Service) for providing the majority of tubers used in this study. NY150 and NYE106 were provided by Walter De Jong (Cornell University). Xin Li (University of British Columbia) provided the homozygous pam16 Arabidopsis thaliana seeds.

\section{LITERATURE CITED}

Babcock, M. J., Eckwall, E. C., and Schottel, J. L. 1993. Production and regulation of potato-scab-inducing phytotoxins by Streptomyces scabies. Microbiology 139:1579-1586.

bacterio.net. 2019. List of prokaryotic names with standing in nomenclature. http://www.bacterio.net

Beauséjour, J., Goyer, C., Vachon, J., and Beaulieu, C. 1999. Production of thaxtomin A by Streptomyces scabies strains in plant extract containing media. Can. J. Microbiol. 45:764-768.

Bignell, D. R. D., Huguet-Tapia, J. C., Joshi, M. V., Pettis, G. S., and Loria, R. 2010. What does it take to be a plant pathogen: Genomic insights from Streptomyces species. Antonie van Leeuwenhoek 98:179-194.

Bouchek-Mechiche, K., Gardan, L., Normand, P., and Jouan, B. 2000. DNA relatedness among strains of Streptomyces pathogenic to potato in France: Description of three new species, $S$. europaeiscabiei sp. nov. and S. stelliscabiei sp. nov. associated with common scab, and S. reticuliscabiei sp. nov. associated with netted scab. Int. J. Syst. Evol. Microbiol. 50:91-99.

Braun, S., Gevens, A., Charkowski, A., Allen, C., and Jansky, S. 2017a. Potato common scab: A review of the causal pathogens, management practices, varietal resistance screening methods, and host resistance. Am. J. Potato Res. 94:283-296.

Braun, S. R., Endelman, J. B., Haynes, K. G., and Jansky, S. H. 2017b. Quantitative trait loci for resistance to common scab and cold-induced sweetening in diploid potato. Plant Genome 10:1-9.

Bukhalid, R. A., and Loria, R. 1997. Cloning and expression of a gene from Streptomyces scabies encoding a putative pathogenicity factor. J. Bacteriol. 179:7776-7783.

Bukhalid, R. A., Takeuchi, T., Labeda, D., and Loria, R. 2002. Horizontal transfer of the plant virulence gene, nec1, and flanking sequences among genetically distinct Streptomyces strains in the Diastatochromogenes cluster. Appl. Environ. Microbiol. 68:738-744.

Cai, X., Li, H., and Liu, A. 2016. A marginal rank-based inverse normal transformation approach to comparing multiple clinical trial endpoints. Stat. Med. 35:3259-3271.

Chater, K. F. 2016. Recent advances in understanding Streptomyces. F1000 Res. 5:2795.

Clark, C. A., and Matthews, S. W. 1987. Histopathology of sweet potato root infection by Streptomyces ipomoea. Phytopathology 77:1418-1423.

Francis, I., Holsters, M., and Vereecke, D. 2010. The Gram-positive side of plant-microbe interactions. Environ. Microbiol. 12:1-12.

Goyer, C., and Beaulieu, C. 1997. Host range of streptomycete strains causing common scab. Plant Dis. 81:901-904.

Haynes, K. G., Wanner, L. A., Thill, C. A., Bradeen, J. M., Miller, J., Novy, R. G., Whitworth, J. L., Corsini, D. L., and Vinyard, B. T. 2010. Common scab trials of potato varieties and advanced selections at three U.S. locations. Am. J. Potato Res. 87:261-276.

Healy, F. G., Wach, M., Krasnoff, S. B., Gibson, D. M., and Loria, R. 2000. The txtAB genes of the plant pathogen Streptomyces acidiscabies encode a peptide synthetase required for phytotoxin thaxtomin A production and pathogenicity. Mol. Microbiol. 38:794-804.

Hiltunen, L. H., Laakso, I., Chobot, V., Hakala, K. S., Weckman, A., and Valkonen, J. P. T. 2006. Influence of thaxtomins in different combinations and concentrations on growth of micropropagated potato shoot cultures. J. Agric. Food Chem. 54:3372-3379.

Huang, Y., Chen, X., Liu, Y., Roth, C., Copeland, C., McFarlane, H. E., Huang, S., Lipka, V., Wiermer, M., and Li, X. 2013. Mitochondrial AtPAM16 is required for plant survival and the negative regulation of plant immunity. Nat. Commun. 4:2558.

International Council for Harmonisation of Technical Requirements for Pharmaceuticals for Human Use. 2005. Validation of Analytical Procedures: Text and Methodology. International Council for Harmonisation of Technical Requirements for Pharmaceuticals for Human Use, Geneva, Switzerland.

Johnson, E. G., Joshi, M. V., Gibson, D. M., and Loria, R. 2007. Cellooligosaccharides released from host plants induce pathogenicity in scabcausing Streptomyces species. Physiol. Mol. Plant Pathol. 71:18-25.

Joshi, M. V., Bignell, D. R. D., Johnson, E. G., Sparks, J. P., Gibson, D. M., and Loria, R. 2007. The AraC/XylS regulator TxtR modulates thaxtomin biosynthesis and virulence in Streptomyces scabies. Mol. Microbiol. 66: 633-642.

Kers, J. A., Cameron, K. D., Joshi, M. V., Bukhalid, R. A., Morello, J. E., Wach, M. J., Gibson, D. M., and Loria, R. 2005. A large, mobile pathogenicity island confers plant pathogenicity on Streptomyces species. Mol. Microbiol. 55:1025-1033.

Kers, J. A., Wach, M. J., Krasnoff, S. B., Widom, J., Cameron, K. D., Bukhalid, R. A., Gibson, D. M., Crane, B. R., and Loria, R. 2004. Nitration of a peptide phytotoxin by bacterial nitric oxide synthase. Nature 429: 79-82. 
Kuznetsova, A., Brockhoff, P. B., and Christensen, R. H. B. 2017. lmerTest package: Tests in linear mixed effects models. J. Stat. Software 82:26.

Lejay, L., Tillard, P., Lepetit, M., Olive, F. D., Filleur, S., Daniel-Vedele, F., and Gojon, A. 1999. Molecular and functional regulation of two NO3uptake systems by $\mathrm{N}$ - and C-status of Arabidopsis plants. Plant J. 18: 509-519.

Lerat, S., Simao-Beaunoir, A.-M., Wu, R., Beaudoin, N., and Beaulieu, C. 2009. Involvement of the plant polymer suberin and the disaccharide cellobiose in triggering thaxtomin A biosynthesis, a phytotoxin produced by the pathogenic agent Streptomyces scabies. Phytopathology 100:91-96.

Li, S., Wang, W., Li, X., Fan, K., and Yang, K. 2015. Genome-wide identification and characterization of reference genes with different transcript abundances for Streptomyces coelicolor. Sci. Rep. 5:15840.

Lindqvist, D. N., Pedersen, H. Æ., and Rasmussen, L. H. 2018. A novel technique for determination of the fructose, glucose and sucrose distribution in nectar from orchids by HPLC-ELSD. J. Chromatogr. B 1081-1082: 126-130.

Loria, R., Bignell, D. R. D., Moll, S., Huguet-Tapia, J. C., Joshi, M. V., Johnson, E. G., Seipke, R. F., and Gibson, D. M. 2008. Thaxtomin biosynthesis: The path to plant pathogenicity in the genus Streptomyces. Antonie van Leeuwenhoek 94:3-10.

Qu, X., Wanner, L. A., and Christ, B. J. 2008. Using the TxtAB operon to quantify pathogenic Streptomyces in potato tubers and soil. Phytopathology 98:405-412.

R Core Team. 2018. R: A language and environment for statistical computing. https://www.R-project.org/
Scheible, W.-R., Fry, B., Kochevenko, A., Schindelasch, D., Zimmerli, L., Somerville, S., Loria, R., and Somerville, C. R. 2003. An Arabidopsis mutant resistant to thaxtomin A, a cellulose synthesis inhibitor from Streptomyces species. Plant Cell 15:1781-1794.

Sousa, J. A. J., and Olivares, F. L. 2016. Plant growth promotion by streptomycetes: Ecophysiology, mechanisms and applications. Chem. Biol. Technol. Agric. 3:24.

Wanner, L. A. 2006. A survey of genetic variation in Streptomyces isolates causing potato common scab in the United States. Phytopathology 96: 1363-1371.

Wanner, L. A. 2009. A patchwork of Streptomyces species isolated from potato common scab lesions in North America. Am. J. Potato Res. 86:247-264.

Wilson, C. R., Luckman, G. A., Tegg, R. S., Yuan, Z. Q., Wilson, A. J., Eyles, A., and Conner, A. J. 2009. Enhanced resistance to common scab of potato through somatic cell selection in cv. Iwa with the phytotoxin thaxtomin A. Plant Pathol. 58:137-144.

Wilson, C. R., Tegg, R. S., Wilson, A. J., Luckman, G. A., Eyles, A., Yuan, Z. Q., Hingston, L. H., and Conner, A. J. 2010. Stable and extreme resistance to common scab of potato obtained through somatic cell selection. Phytopathology 100:460-467.

Zhang, Y., Bignell, D. R. D., Zuo, R., Fan, Q., Huguet-Tapia, J. C., Ding, Y., and Loria, R. 2016. Promiscuous pathogenicity islands and phylogeny of pathogenic Streptomyces spp. Mol. Plant-Microbe Interact. 29:640-650.

Zhou, B., Zhang, M. S., and Ma, X. K. 2017. First report of Streptomyces bottropensis causing potato common scab in Hebei Province, China. Plant Dis. 101:502. 